\title{
Reflux gastritis in the intact stomach
}

\author{
G M Sobala, R F G King, A T R Axon, M F Dixon
}

\begin{abstract}
Gastric biopsy specimens from patients who have undergone gastric surgery frequently exhibit foveolar hyperplasia, oedema, vasodilatation and congestion, and a paucity of inflammatory cells as consequences of entero-gastric reflux. Similar, albeit generally milder, changes were found in 47 of 316 (15\%) non-surgical patients undergoing endoscopy for dyspeptic symptoms. To relate these changes to bile reflux or other potential gastric irritants the total bile acid concentration was measured in samples of fasting gastric juice, and the use of a symptom questionnaire ascertained the patients' cigarette consumption, use of nonsteroidal anti-inflammatory drugs (NSAIDs), and alcohol intake. When patients with reflux gastritis were compared with normal controls $(n=91)$, significant increases in associated peptic ulceration and NSAID use were found in the group with reflux, but no increases in bile acid concentrations. Indeed, only one patient had evidence of duodenogastric reflux.

It is concluded that most cases of "reflux gastritis" in the intact stomach are not due to reflux of bile. Our findings indicate an important pathogenic role for long term NSAID use, in what might be usefully termed type C or "chemical" gastritis.
\end{abstract}

A distinctive histological picture has recently been recognised in biopsy specimens taken from postoperative stomachs: it is characterised by foveolar elongation, tortuosity and hypercellularity, together with oedema, vasodilatation, congestion and a paucity of inflammatory cells in the lamina propria. ${ }^{1}$ It is correlated with objective measures of enterogastric bile reflux, and has therefore been termed "reflux gastritis". These histological features, however, are not confined to the postoperative stomach and we have previously seen similar changes in 35 of 205 non-surgical patients with non-ulcer dyspepsia. ${ }^{2}$ This is a substantial proportion, and is difficult to attribute to abnormal duodenogastric bile reflux alone. We have therefore hypothesised that this histological picture may, in fact, be a non-specific response to a variety of gastric irritants, bile being just one.

The aim of this study was to confirm the prevalence of "reflux gastritis" in the intact stomach, to examine its relation with gastroduodenal pathology, and to determine whether it is associated with high alcohol intake, use of non-steroidal anti-inflammatory agents (NSAIDs) or total bile acid concentrations in fasting gastric juice as a measure of duodenogastric reflux. It was decided for two reasons that the chief analyses should be between those patients diagnosed as having reflux gastritis and those with normal antral histology. Firstly, because before reflux gastritis was recognised as a separate entity, almost all such biopsy specimens would have been reported as being within normal limits; and secondly, we considered that any possible effects of irritants on the gastric mucosa would be masked by the more obvious sequelae of Helicobacter pylori (previously known as Campylobacter pylori ${ }^{3}$ ) infection in those patients with type B chronic gastritis. $^{2}$

\section{Patients and methods}

Biopsy specimens were obtained from patients participating in a study investigating possible associations between dyspeptic symptoms and $H$ pylori. Over 12 months two antral biopsy specimens were taken from each of 316 patients attending an endoscopy clinic with symptoms of dyspepsia. Patients with previous gastric surgery were excluded. All patients were given a "symptom questionnaire" which included detailed questions about alcohol intake and use of NSAIDs. Alcohol consumption was recorded in terms of units per week; use of NSAIDs was recorded on a four point scale $(0$ $=$ none at all; $1=$ several times a month; $2=$ several times a week; 3 = daily).

\section{MEASUREMENT OF TOTAL BILE ACID}

In 110 patients $5 \mathrm{ml}$ of fasting gastric juice were aspirated into a clean container and then stored at $-20^{\circ} \mathrm{C}$ for analysis within three months. Total bile acid concentrations were then measured using the previously described steroid dehydrogenase method. ${ }^{4}$ By this method a bile acid concentration of $>1 \mathrm{mmol} / 1$ is regarded as abnormal and indicative of clinically important duodenogastric reflux. ${ }^{5}$

The biopsy specimens were immediately fixed in $10 \%$ formalin and routinely processed. Paraffin wax sections were cut at three levels and stained by haematoxylin and eosin. Additional sections taken at level 2 were stained with the modified Giemsa technique for $H$ pylori. All sections were examined by the same pathologist (MFD) without knowledge of other patient data. The presence of foveolar hyper-
Dr M F Dixon, Departmen of Pathology, University of Leeds LS2 9JT.

Accepted for publication 16 November 1989 
Table 1 Demographic details, prevalence of ulcer disease, and $H$ pylori infection by histological group

\begin{tabular}{llllllc}
\hline Histology & $n=\begin{array}{l}\text { Mean } \\
\text { age }\end{array}$ & Range & Male & $\begin{array}{l}\text { Ulcer } \\
\text { disease }\end{array}$ & $\begin{array}{c}\text { Percentage } \\
\text { positive }\end{array}$ \\
\hline $\begin{array}{l}\text { Normal } \\
\begin{array}{l}\text { Chronic superficial } \\
\quad \text { gastritis }\end{array}\end{array}$ & 91 & $38 \cdot 8$ & $(18-70)$ & $53 \cdot 9 \%$ & $3.3 \%$ & $3 \cdot 3$ \\
$\begin{array}{l}\text { Chronic atrophic } \\
\quad \text { gastritis }\end{array}$ & 97 & $43 \cdot 7^{\star}$ & $(18-69)$ & $58 \cdot 8 \%$ & $33 \% \dagger$ & $92 \cdot 8 \dagger$ \\
$\begin{array}{l}\text { Reflux gastritis } \\
\text { Lymphocytic gastritis }\end{array}$ & 47 & $48 \cdot 1 \dagger$ & $(19-74)$ & $58 \cdot 4 \%$ & $45 \cdot 5 \% \dagger$ & $94 \cdot 8 \dagger$ \\
\hline
\end{tabular}

Group differs from controls: ${ }^{\star}=p<0.05 ; \dagger=p<0.001$.

Table 2 Prevalence of possible risk factors (gastric irritants) in patients with normal histology and reflux gastritis

\begin{tabular}{|c|c|c|c|c|}
\hline Histology & $\begin{array}{l}\text { Perecentage of } \\
\text { smokers }\end{array}$ & $\begin{array}{l}\text { Percentage of } \\
\text { patients } \\
\text { taking } \\
\text { NSAIDs }\end{array}$ & $\begin{array}{l}\text { Percentage of } \\
\text { heavy } \\
\text { drinkers } \\
\text { (>30 units/week) }\end{array}$ & $\begin{array}{l}\text { High bile } \\
\text { acid } \\
(>1 \mathrm{mmol} / \mathrm{l})\end{array}$ \\
\hline $\begin{array}{l}\text { Normal } \\
\text { Reflux gastritis }\end{array}$ & $\begin{array}{l}40 \cdot 8(n=76) \\
43 \cdot 2(n=37) \\
\text { n.s. }\end{array}$ & $\begin{array}{l}6.6(\mathrm{n}=76) \\
21.6(\mathrm{n}=37) \\
\mathrm{p}<0.05\end{array}$ & $\begin{array}{l}7.9(n=76) \\
16.2(n=37) \\
p=0.15\end{array}$ & $\begin{array}{l}0 \text { of } 27 \\
1 \text { of } 23 \\
\text { n.s. }\end{array}$ \\
\hline
\end{tabular}

plasia, lamina propria oedema, and vascular congestion were scored on a scale of 0 (none) to 3 (severe), and these were added to two scores (0 to 3 ) for paucity of acute and chronic inflammatory cells, respectively, to give a total reflux score (minimum 0, maximum 15). On the basis of previous work, patients with reflux scores of 11 or more were considered to have "reflux gastritis".

Comparisons between groups were performed with standard non-parametric rank tests for ordinal data, and Fisher's exact test for nominal data using the SAS statistics package on a mainframe computer. ${ }^{6}$

\section{Results}

Five different patterns of antral histology were idetotified: (i) normal; (ii) chronic superficial gastritis; (iii) chronic atrophic gastritis; (iv) reflux gastritis; and (v) lymphocytic gastritis. The demographic details of these five groups, together with the prevalence of ulcer disease and $H$ pylori infection are shown in table 1 . Patients with chronic gastritis or lymphocytic

Figure 1 (a) Antral biopsy specimens from a patient taking aspirin regularly, showing mild foveolar elongation and tortuosity; ( $b$ ) higher power view showing increased cellularity of the foveolae with nuclear enlargement, some nuclear "crowding" at the surface, and mild mucin depletion. gastritis were excluded from further analysis, leaving 47 with reflux gastritis and 91 with normal histology.

There were no significant differences in age or sex distribution between patients with normal histology and reflux gastritis, but significantly more patients with reflux gastritis had peptic ulcers (oesophageal, gastric, pyloric or duodenal) than did patients with normal histology.

\section{POSSIBLE GASTRIC IRRITANTS}

Of the 138 patients with either normal histology or reflux gastritis, $113(81.9 \%)$ responded to the questionnaire (table 2). Cigarette consumption did not differ significantly between the normal and reflux gastritis groups, but significantly more patients in the group with reflux gastritis were taking NSAIDs. Fig 1 shows changes of reflux gastritis in a patient taking aspirin daily. There was a significant correlation between NSAID use and the total reflux score, as well as with foveolar hyperplasia and vascular congestion (table 3 ). Although there was a trend towards more patients in the group with reflux gastritis being heavy drinkers, this did not reach significance. Fig 2 shows the reflux gastritis in a patient consuming 40 units of alcohol a week. There were no differences in median gastric fasting total bile salt concentrations between control and patient histology in the 49 people in both groups in whom it was measured. Only one patient in these two groups had an abnormal bile acid concentration and he also had reflux gastritis (fig 3).

\section{Discussion}

Although the histological features of reflux gastritis were originally described in postoperative stomachs in association with enterogastric bile reflux, our results confirm that they are often found in dyspeptic subjects with intact stomachs. The absence of an inflam-

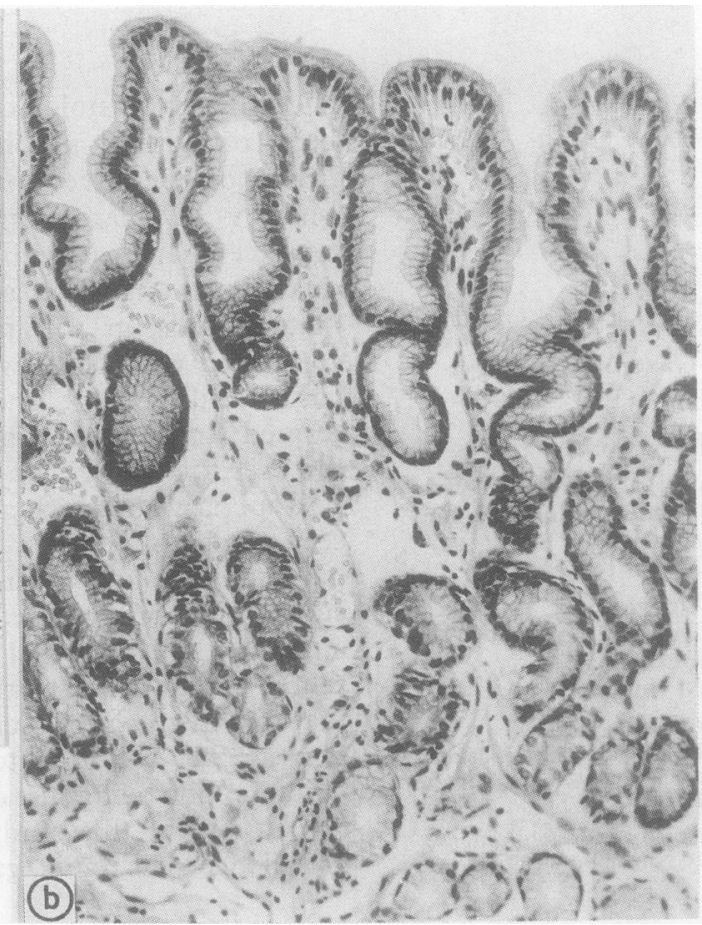


Table 3 Correlation between histological features and prevalence of ingestion of NSAIDs

\begin{tabular}{lll}
\hline & $\begin{array}{l}\text { Spearman } \\
\text { correlation } \\
\text { coefficient }\end{array}$ & $p$ Value \\
\hline Histological feature & 0.21 & $\mathrm{p}=0.03$ \\
\hline Foveolar hyperplasia & 0.08 & $\mathrm{NS}$ \\
Lamina propria oedema & 0.20 & $\mathrm{p}=0.03$ \\
Vascular congestion & 0.24 & $\mathrm{p}=0.01$ \\
Histological reflux score & & \\
\hline
\end{tabular}

matory cell infiltrate in this condition has hampered its recognition by pathologists: most such biopsy specimens would previously have been passed as normal. Our finding of a higher incidence of ulcer disease in the group with reflux gastritis compared with controls, however, supports the notion that this is a separate pathological entity. The association with gastroduodenal ulcers suggests that there are common aetiological factors for both reflux gastritis and ulcer disease. Alternatively, some cases of antral reflux gastritis may be secondary to duodenal ulcer disease if this has led to pyloroduodenal scarring and facilitated enterogastric bile reflux. Reflux gastritis may then replace the original condition of antral $H$ pylori associated chronic gastritis generally present in patients with duodenal ulcers. Our study again confirms the strong negative correlation between $H$ pylori and the histological picture of reflux gastritis. ${ }^{7}$

The finding of an increased gastric bile acid concentration in only one of 23 cases of reflux gastritis in intact stomachs contrasts with a rate of 11 out of 27 in mostly postoperative patients in our previous study. ${ }^{1}$ A single estimation of fasting gastric juice bile acid concentration may not be a specific measure of bile reflux in any one patient, but it has been shown to give an accurate representation of bile reflux in a population. ${ }^{8}$ This result therefore indicates that "reflux gastritis" is usually caused by agents other than bile in the non-surgical stomach.

Our search for other causative agents was only partially successful. Nevertheless, we have

Figure 2 (a) Antral mucosa from 41 year old man who drinks 40 units of alcohol a week. There is elongation and distortion of foveolae with mild oedema of the superficial lamina propria. (b) Higher power view of another biopsy specimen from this subject shows nuclear crowding in the foveolae and glandular atrophy with lamina propria fibrosis. established a clear association between use of NSAIDs and the presence of the histological picture of "reflux gastritis". While the role of NSAIDs in causing acute erosive gastritis and haemorrhage in both experimental animals and man is well documented, ${ }^{9}$ there have been few histological studies on the effects of long term use. Until recently their possible effects on the gastric mucosa have invariably been assessed in terms of an acute and chronic inflammatory cell response. It is now appreciated, however, that chronic mucosal inflammation is widely prevalent in the age group of patients who take NSAIDs and that this is a consequence of $H$ pylori colonisation. In $H$ pylori positive cases the associated chronic gastritis dominates the histological appearances and masks any damage caused by NSAIDs. Thus it is not surprising that a study from the era before $H$ pylori concluded that the presence and severity of chronic gastritis remained unaffected by four weeks of treatment with NSAIDs. ${ }^{10}$ Even recent studies on patients taking NSAIDs where $H$ pylori has been sought have failed to distinguish changes induced by these drugs from $H$ pylori-related inflammation by separate consideration of biopsy specimens from $H$ pylori positive and negative cases and comparison with positive and negative control subjects not taking NSAIDs. ${ }^{112}$ That there are epithelial changes brought about by NSAIDs, which are unrelated to $H$ pylori and inflammatory cell infiltration, is indicated by a detailed study on 13 patients with drug induced gastric erosions, ${ }^{13}$ and further support comes from a description of "gastric adaptation" to chronic aspirin ingestion in which it was found that surface epithelial regeneration and vascular congestion were more common after treatment. ${ }^{14}$ Interestingly, this study also reported changes of atrophy associated with treatment: in our patients those taking NSAIDs were also more likely to exhibit atrophy (Spearman rank correlation coefficient $\mathrm{r}=0.29 ; \mathrm{p}=0.002$ )

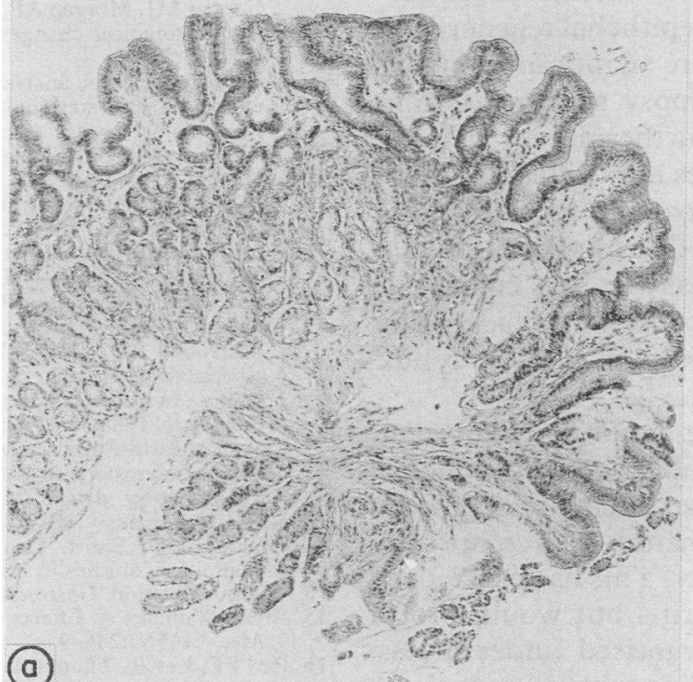

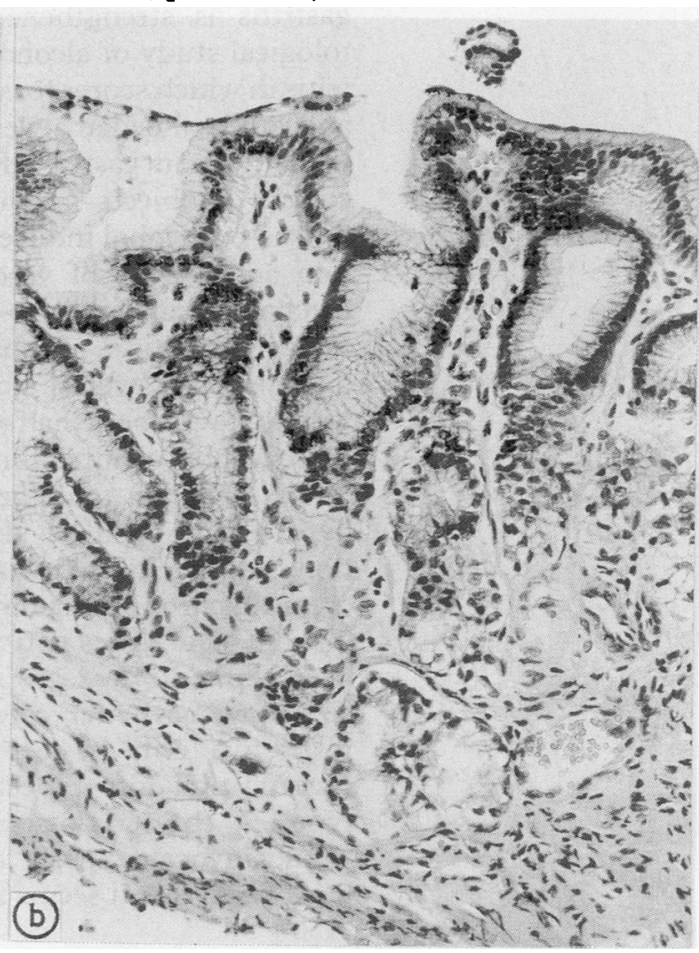


Figure 3 (a) Foveolar hyperplasia and distortion is evident in this antral biopsy specimen from the patient with confirmed bile reflux (gastric juice bile acids $=7.05 \mathrm{mmol} / \mathrm{l})$. Although a basal aggregate of lymphocytes is present, higher magnification (b) shows very few inflammatory cells in the superficial lamina propria and confirms foveolar and surface hypercellularity and mucin depletion.

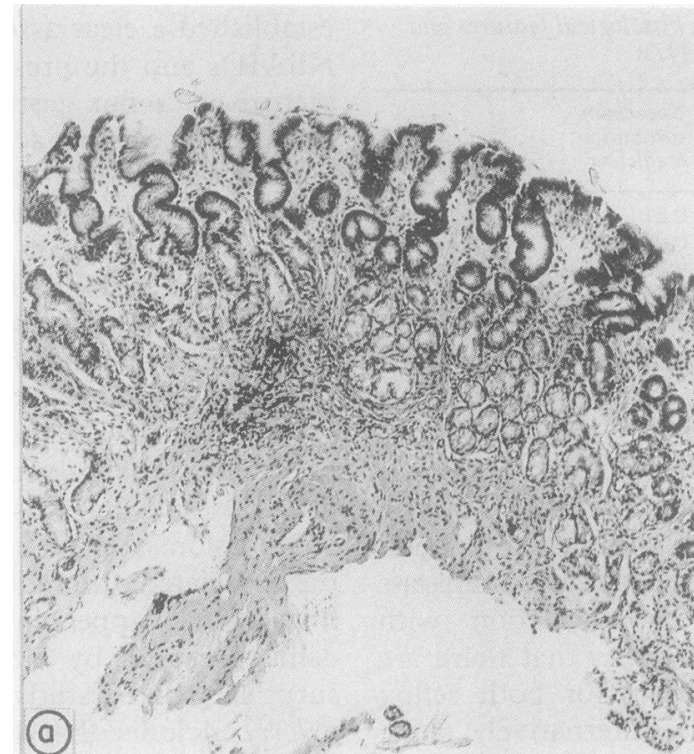

We were unable to identify with certainty any other predisposing factors for reflux gastritis, although there was a non-significant trend towards an association with high alcohol intake. Again previous studies of gastritis in alcoholics have been confounded (with hindsight) by the interplay with $H$ pylori related gastritis. Nevertheless, some relevant observations emerge from previous reports on the subject. Williams comments that "inflammatory lesions were notably slight or entirely absent, even in some inveterate spirit drinkers," and one of his cases showed widespread hyperplasia of the surface epithelium. ${ }^{15}$ On the other hand, Parl found a higher incidence of chronic gastritis in alcoholic patients compared with controls, but also described, "formation of villi in the antrum with . . . extensive epithelial regeneration even in the absence of acute mucosal damage". ${ }^{16}$ This anecdotal evidence for a pattern of response distinct from chronic gastritis is strengthened by a detailed histological study of alcoholic haemorrhagic gastritis in which scores for epithelial regeneration and mucosal oedema were significantly higher than those in gastric biopsy specimens from control subjects. ${ }^{17}$ Furthermore, damage caused by alcohol induces mast cell degranulation and release of vasoactive mediators, ${ }^{18}$ a mechanism analagous to that implicated in bile reflux gastritis. ${ }^{19}$ It has to be conceded, however, that even if alcohol was a factor this would leave about half of our cases of reflux gastritis unaccounted for.

We conclude that the findings of foveolar hyperplasia, capillary dilatation and congestion, and lamina propria oedema with no increase in chronic inflammatory cells comprise a distinct histological entity. This has previously been termed reflux gastritis but would probably now be better categorised under a less restrictive term. In keeping with our previous classification into type $A$ (autoimmune) and type B (bacteria-associated) gastritis, ${ }^{3}$ we would advocate type C "chemical" gastritis for this category as it seems to be a consequence of

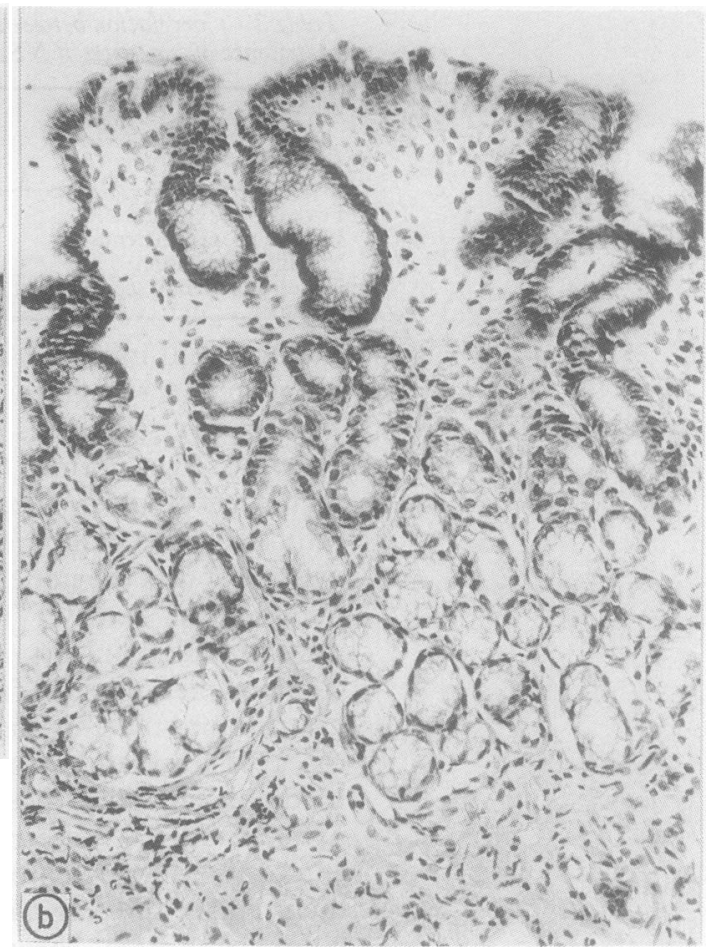

gastric irritation by bile constituents, NSAIDs, or other, as yet unidentified, agents.

1 Dixon MF, O'Connor HJ, Axon ATR, King RFJG Johnston D. Reflux gastritis: distinct histopathological entity? J Clin Pathol 1986;39:524-30.

2 Wyatt JI, Dixon MF. Chronic gastritis-a pathogenetic approach. J Pathol 1988;154:113-24.

3 Goodwin CS, Armstrong JA, Chilvers T, et al. Transfer of Campylobacter pylori and Campylobacter mustelae to Helicobacter gen. nov. as Helicobacter pylori comb. nov. and Helicobacter mustelae comb. nov. respectively. International Journal of Systematic Bacteriology 1989;39. 397-405.

4 Dewar EP, King RFGJ, Johnston D. Bile acid and lysolecithin concentrations in the stomach of patients with gastric ulcer: before operation and after treatment by highly selective vagotomy, Billroth I partial gastrectomy and truncal vagotomy and pyloroplasty. Br J Surg 1983; 70:401-5.

5 Rhodes J, Barnardo DE, Phillips SF, Rovelstad PA, Hofmann AF. Increased reflux of bile into the stomach in patients with gastric ulcer. Gastroenterology 1969;57: patients

6 SAS user's guide: statistics. Version 5 edition. Cary, North Carolina: SAS Institute Inc, 1985

7 O'Connor HJ, Wyatt JI, Dixon MF, Axon ATR. Campylobacter like organisms and reflux gastritis. J Clin Pathol 1986;39:531-4.

8 Houghton PWJ, Mortensen NJMcC, Thomas WEG, Cooper MJ, Morgan AP, Burton P. Intragastric bile acids and histological changes in gastric mucosa. Br J Surg 1986;73:354-6.

9 Rainsford KD. An analysis of the gastro-intestinal sideeffects on non-steroidal anti-inflammatory drugs, with particular reference to comparative studies in man and laboratory species. Rheumatol Int 1982;2:1-10.

10 McIntyre RLE, Irani MS, Piris J. Histological study of the effects of three anti-inflammatory preparations on the effects of three anti-inflammatory preparations

11 Doube A, Morris A. Nonsteroidal anti-inflammatory druginduced dyspepsia - is Campylobacter pyloridis implicated? BrJ Rheumatol 1988;27:110-2.

12 Upadhyay R, Howatson A, McKinlay A, Danesh BJZ Sturrock RD, Russell RI. Campylobacter pylori associated gastritis in patients with rheumatoid arthritis taking nonsteroidal anti-inflammatory drugs. $\mathrm{Br}$ Rheumatol 1988;27:113-6.

13 Laine L, Marin-Sorensen M, Weinstein WM. The histology of gastric erosions in patients taking non-steroidal antiins ins : a prospective study. Gastroenterology 1988;94:A247.

14 Graham DY, Smith JL, Spjut HJ, Torres E. Gastric adaptation: studies in humans during continuous aspirin adaptation: studies in humans during continuous

15 Wynn Williams A. Effects of alcohol on gastric mucosa. $\mathrm{Br}$ Med J 1956;i:256-9.

16 Parl FF, Lev R, Thomas E, Pitchumoni CS. Histologic and morphometric study of chronic gastritis in alcoholic morphometric study of chronic gastr

17 Laine L, Weinstein WM. Histology of alcoholic hemorrhagic "gastritis": a prospective evaluation. Gastrohagic "gastritis": a prosp
enterology 1988;94:1254-62.

18 Oates PJ, Hakkinen JP. Studies on the mechanism of ethanol-induced gastric damage in rats. Gastroenterology 1988;94:10-21.

19 Rees W, Rhodes J. Bile reflux in gastro-oesophageal disease. Clin Gastroenterol 1977;6:179-200. 